\title{
Kinetic Study on Solid-Liquid Extraction of Condensed Tannins from Rosa Canina Branches and Stems
}

\author{
OANA TEODORA CIUPERCA ${ }^{1,2}$, CARMEN ELENA TEBRENCU ${ }^{2,3}$, LILIANA LAZAR $^{1 *}$, \\ IRINA VOLF ${ }^{*}$ \\ 1"Gheorghe Asachi" Technical University of Iasi, Faculty of Chemical Engineering and Environmental Protection, 73 Prof. D. Mangeron \\ Str., 700050, Iasi, Romania \\ ${ }^{2}$ Research and Processing Centre for Medicinal Plants PLANTAVOREL S.A., 46 Cuza Voda Str., 610144, Piatra Neamt, Romania \\ ${ }^{3}$ Academy of Romanian Scientists, 54 Splaiul Independentei, 050094, Bucharest, Romania
}

\begin{abstract}
The goal of this study was to point out the effect of parameters (solvent, solid to solvent ratio and extraction time) on the extraction of condensed tannins from Rosa canina feedstock, using conventional methods such as room temperature extraction (RTE) and heat reflux extraction (HRE). Moreover, the extraction kinetics behaviour for HRE has been extensively studied in order to foreshadow a scale up process. The second order rate model was applied to estimate the extraction kinetics of a conventional heat reflux extraction (HRE) at different solid to liquid ratios, concentrations of solvent extraction times. Results showed that the second order rate model was the rate-governing step of the extraction process, and the predicted and experimental data fits very well.
\end{abstract}

Keywords: Rosa canina, branches, stems, room temperature extraction, heat reflux extraction, kinetics

\section{Introduction}

Plants are rich in secondary metabolites such as alkaloids, steroids, glycosides, volatile oils, resins, phenolic acids, flavonoids and tannins, which are present in root, bark, branches, stems, leaves, flowers, fruits or seeds [1]. Any of these classes are of increasing interest due to their applications in pharmaceutical, nutritional, cosmetic, industrial or even environmental field. The beneficial action of phytochemicals typically comes from the merging or their synergic actions [2-4].

By far, polyphenols are the most studied secondary metabolites due to their bioactive potential. Polyphenols are known as antioxidants, antibacterial, anti-inflammatory, anti-diabetic and chelating agents [5]. The significant antioxidant activity of natural polyphenols is presumed to exert effects such as anti-carcinogenic, anti-mutagenic [6], and cardio-protective, linked to their free radical scavenging [7]. Moreover, polyphenols may be used as natural pigments and preservatives for foods, as cosmetics additives, or in paper and paints industry [8]. Also, polyphenols have an important influence on microorganisms [9] and on plant growth and development [10].

The extraction of polyphenols from biomass presents many economic and environmental benefits since the feedstock comes in large amounts as waste and its valorisation is achieved in a sustainable way. Rosa canina grows wild in wide areas of Europe, North Africa and West Asia. It is a perennial and deciduous shrub, ranging in height from $2-3$ meters that has slender stems with thorns and is highly resistant to poor and dry rocky soils [11]. Different parts of this plant have been traditionally used to treat various diseases. Root has been used to cure cough, haemorrhoid and dysuria while leaves were used in the treatment of the common cold, influenza and cough. Furthermore, its fruit has been utilized in the treatment of asthma, bronchitis and common cold. Finally, seeds have been used to treat osteoarthritis, rheumatism and gout [12]. The beneficial properties of Rosa canina may, to some extent, be related to the polyphenols and high amount of vitamin C. Branches and stems of Rosa canina, resulting as wastes from cutting maintenance, could represent a new source of polyphenols, mainly condensed tannins, that can be obtained using different extraction methods [13].

*email: lillazar@tuiasi.ro,iwolf@tuiasi.ro 
The extraction of the polyphenols is connected to the solubility of the target molecules in a large range of solvents. The solvent moves into the vegetal matrix and solubilize the compounds with similar polarity. There are well known several conventional extraction techniques as well as some nonconventional, developed more recently [14-16]. The conventional techniques (solid-liquid extraction at room temperature or using heat reflux) use organic solvents (hexane, acetone, methanol, ethanol etc.) or water and are carried out generally at atmospheric pressure and moderate temperature, while new techniques are using some intensification actions (microwave, ultrasound, supercritical fluids) in order to reduce the amount of solvent and easily disrupt the vegetal matrix $[17,18]$.

Regarding conventional or nonconventional, the extraction method must be simple, fast, cost effective and with large applicability. However, even if both conventional and green extraction techniques were widely used and have been critically reviewed in the last decade [5,19] extensive experiments are required to understand, modelling and optimize each extraction process. Even if the green methods are more suitable in terms of impact and efficiency [19], in common practice, for qualitative assessment of new bioresources, the simple extraction techniques are often used.

The goal of this work was to point out the effect of parameters (solvent, solid to liquid ratio and extraction time) on the extraction of condensed tannins from Rosa canina feedstock, using conventional extraction techniques, in order to understand and highlight the kinetic mechanism. Therefore, the experiments involved two steps: the first consisted in a preliminary study of kinetic models depicted in literature, while in the second one, the extraction of condensed tannins was interpreted using a second-order kinetic model to predict the extraction constant rate $(k)$, the concentration of polyphenols at equilibrium $\left(C_{e}\right)$ and the initial constant rate $(h)$.

\section{Materials and methods}

\subsection{Materials and samples preparation}

The feedstock consisted in young branches and stems of Rosa canina L. (Rosaceae) collected from Siret Valley, Bacău county, Romania, in September 2016. The biomass was dried in a well-ventilated room, in a single layer, protected from direct solar light. After drying, the material was milled in a Microtron MB550 equipment and mechanically separated using a vibratory system to particle sizes of $0.1<\Phi \leq 0.5 \mathrm{~mm}$. The feedstock was stored in a clean desiccator until extraction. All the standards and chemicals were pure or of analytical grade (Sigma Aldrich, Merck, Roth).

\subsection{Research methodology}

The influence of extraction parameters on condensed tannins separation from branches of Rosa canina were studied applying two of well-used solid-liquid extraction methods: heat reflux extraction (HRE) and room temperature extraction (RTE) following the experimental setup presented in Figure 1.

For heat reflux extraction (HRE), a round bottom flask, an ascendant condenser and a Precisterm thermostatic water bath were used while for room temperature extraction (RTE), the flasks were placed in a dark place and recurrently stirred. Three parameters affecting the extraction process were considered in this study: the solvent concentration, solid to liquid ratio and the extraction time.

The effects of solvent concentration: $5 \mathrm{~g}$ of biomass with particle size of $0.1-0.5 \mathrm{~mm}$ were extracted for 120 minutes, using a solid to liquid ratio 1:10 and as solvent: distilled water and 30, 50, $70,96 \%$ v/v ethanol-water mixture, within a range of temperatures between 80 and $100{ }^{\circ} \mathrm{C}$.

The effects of solid to liquid ratio and extraction time. For HRE: $5 \mathrm{~g}$ of biomass were mixed with $40,50,60,75 \mathrm{~mL}$ ethanol-water mixture $50 \% \mathrm{v} / \mathrm{v}$ corresponding to solid to solvent ratio of 1:8, 1:10, 1:12, 1:15. The extraction was performed at $80{ }^{\circ} \mathrm{C}$ for $30,60,90$ and $120 \mathrm{~min}$. For RTE: $5 \mathrm{~g}$ biomass were mixed with $25,40,50,60,75 \mathrm{~mL}$ ethanol-water $50 \% \mathrm{v} / \mathrm{v}$, corresponding to a solid to solvent ratio of 1:5, 1:8, 1:10, 1:12, 1:15. The extraction was performed at $20-23{ }^{\circ} \mathrm{C}$ for 7 days; all samples were stored in a dark place and recurrently stirred. 


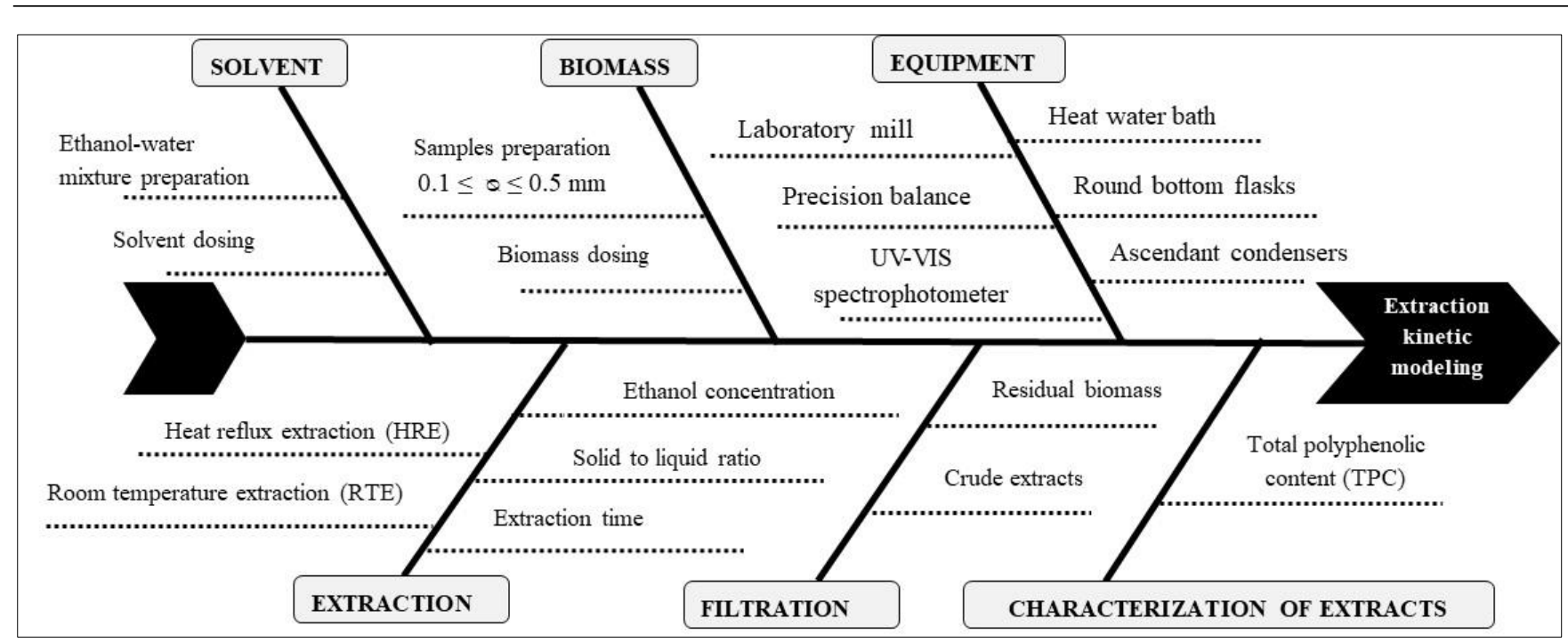

Figure 1. Experimental setup

\subsection{Data analysis and processing}

The quantitative evaluation of the crude extracts was performed by assessing of total polyphenolic content (expressed in catechin) following the aluminium chloride colorimetric assay [20]. The absorbance of solutions was recorded at $510 \mathrm{~nm}$, against distilled water, using an Agilent UV-VIS Cary 50 Spectrophotometer. The concentration of total phenolics content was calculated from the calibration curve $\left(\mathrm{Y}=0.9268 \mathrm{X}+0.0233, \mathrm{R}^{2}=0.9992\right)$ and expressed as $\mathrm{mg}$ catechin equivalent $(\mathrm{CE})$ per $\mathrm{g}$ of biomass (mg CE /g). All processes were carried out in triplicate.

\subsection{Modelling of solid-liquid extraction}

The literature reported several kinetic models that imagine the batch solid-liquid extraction techniques. The list include Fick's law of diffusion (unsteady diffusion), parabolic diffusion (WeberMorris model), hyperbolic sorption-desorption (Peleg model), rate law (second order model), power law (Page model), Weilbull's and Elovich's models [21-25].

A second-order rate law gives the best fits for the extraction rate of polyphenols in a solid-liquid conventional extraction process. The rate of target molecules dissolution is given in Eq. (1):

$$
\frac{\mathrm{dC}_{\mathrm{t}}}{\mathrm{dt}}=\mathrm{k}\left(\mathrm{C}_{\mathrm{e}}-\mathrm{C}_{\mathrm{t}}\right)^{2}
$$

where: $k$ is the second-order extraction rate constant $(\mathrm{mL} / \mathrm{g} \cdot \mathrm{min}), C_{t}$ is the concentration of total polyphenols, expressed in catechin $(\mathrm{mg} \mathrm{TPC} / \mathrm{mL})$ at a given extraction time $t(\mathrm{~min}), C_{e}$ is the concentration of total polyphenols, expressed in catechin $(\mathrm{mg} \mathrm{TPC} / \mathrm{mL})$ at equilibrium in the crude extract.

Considering the initial and boundary conditions as $t=0$ to $t$ and $C_{t}=0$ to $C_{t}$, the integrated rate law can be obtained Eq. (2):

$$
\mathrm{C}_{\mathrm{t}}=\frac{\mathrm{C}_{\mathrm{e}}^{2} \cdot \mathrm{k} \cdot \mathrm{t}}{1+\mathrm{C}_{\mathrm{e}} \cdot \mathrm{k} \cdot \mathrm{t}}
$$

The constant rate $k$ can be determined by fitting linear transformation of Eq. (2) with experimental data, using Eq. (3):

$$
\frac{\mathrm{t}}{\mathrm{C}_{\mathrm{t}}}=\frac{1}{\mathrm{k} \cdot \mathrm{C}_{\mathrm{e}}^{2}}+\frac{\mathrm{t}}{\mathrm{C}_{\mathrm{e}}}
$$


The concentration of total polyphenols in the extraction solvent at any time can be described as Eq. (4):

$$
\mathrm{C}_{\mathrm{t}}=\frac{\mathrm{t}}{(1 / \mathrm{h})+\left(\mathrm{t} / \mathrm{C}_{\mathrm{e}}\right)}
$$

where: $h$ is the initial extraction rate $(\mathrm{g} / \mathrm{mL} \cdot \mathrm{min})$ when the extraction time $t$ approaches to zero.

The determination of kinetic parameters is the most important step in order to design an efficient solid-liquid extraction process. The initial extraction rate $(h)$, the concentration of total polyphenols (expressed in catechin) at equilibrium $\left(C_{e}\right)$, and the second-order extraction constant rate $(k)$ can be determined experimentally from the slope and intercept by plotting $t / C_{t} \mathrm{vs}$. $t$.

\subsection{Statistical methods}

Parameters of the second-order rate law model were calculated from their linearized forms by the linear regression. The concordance between experimental data $\left(C_{t}^{\exp }\right)$ and calculated $\left(C_{t}^{\text {model }}\right)$ values was determinate by linear correlation coefficient and the root mean square (RMS) computed using the following:

$$
\mathrm{RMS}=\sqrt{\frac{1}{\mathrm{~N}} \sum_{\mathrm{i}=1}^{\mathrm{N}}\left(\frac{\mathrm{C}_{\mathrm{t}}^{\mathrm{exp}}-\mathrm{C}_{\mathrm{t}}^{\text {model }}}{\mathrm{C}_{\mathrm{t}}^{\exp }}\right)^{2}}
$$

\section{Results and discussions}

\subsection{Influence of solvent concentration and solid to liquid ratio}

The solvent concentration and the solid to liquid ratio are two important parameters of extraction processes. The study of these two parameters performed on two conventional extraction methods HRE and RTE revealed the TPC was significant influenced by the solvent concentration of (Figure 2) as well as by the solid to liquid ratio (Figure 3 ).

Moreover, the comparative study shows that HRE method lead to higher concentrations of condensed tannins. The TPC increases with the increase of solvent concentration up to $50 \% \mathrm{v} / \mathrm{v}$ EtOH-water. The result is in good agreement to other study assuming that a higher water content caused the solvent mixture to the reach of a polarity degree not favourable for the extraction [26-28].

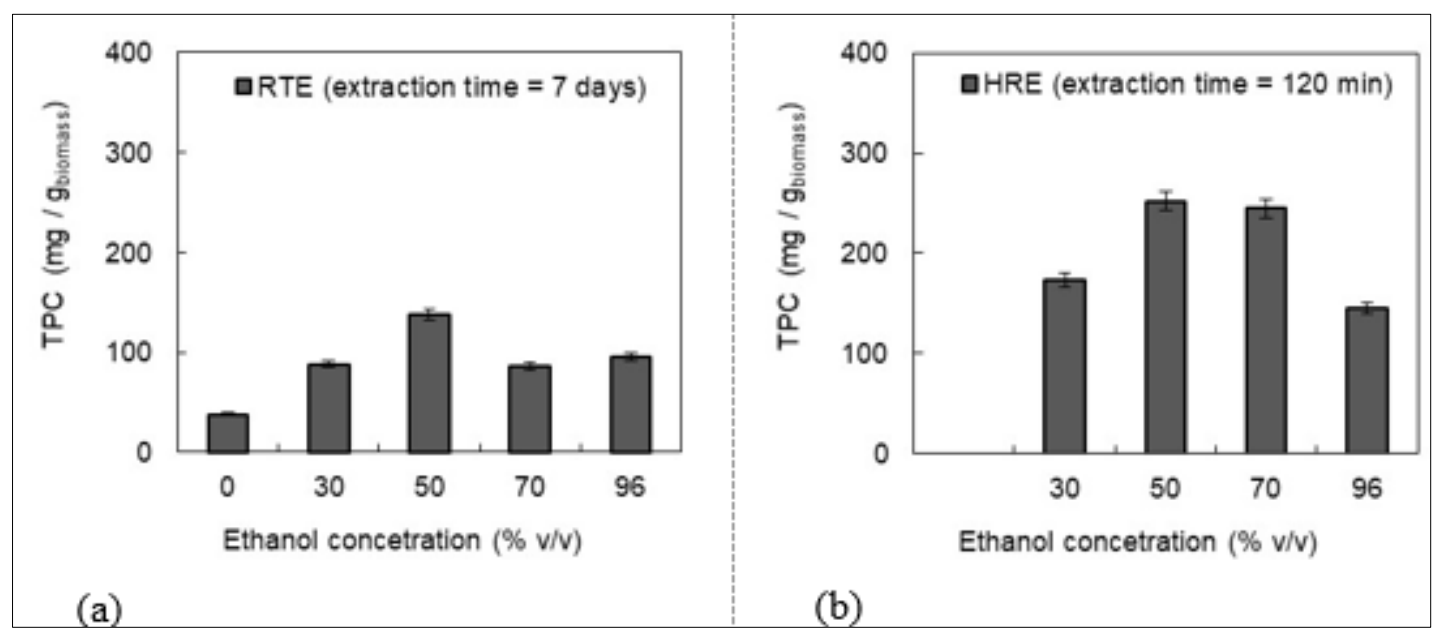

Figure 2. Influence of the solvent concentration on the TPC extraction from Rosa canina branches and steams using RTE (a) and HRE (b) methods 


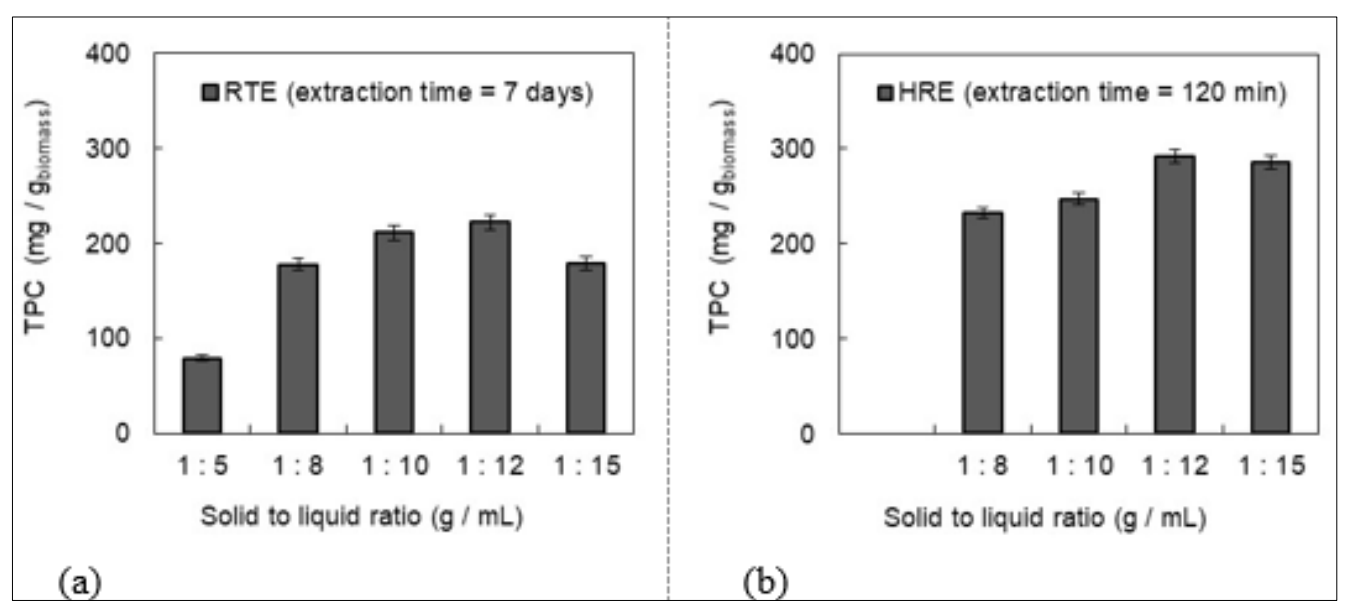

Figure 3. Influence of the solid to liquid ratio on TPC extraction from Rosa canina branches and steams using RTE (a) and HRE (b) methods

The total phenolic content increases with the increase of solid to liquid ratio to $1: 12$, after which the influence of this ratio is negative. However, for practical applications and scale up processes a 1:10 ratio have to be usually preferred considering the physical properties of ethanol as well as solvent and purification costs. In this case the total polyphenols_expressed in catechin) yield is close to that resulted using a 1:12 ratio while the process is cost effective.

\subsection{Influence of extraction time}

The study on extraction time influence was performed only for HRE method in the range of 0 $120 \mathrm{~min}$ at different solid to liquid ratio $(1: 8,1: 10,1: 12$ and 1:15), using $5 \mathrm{~g}$ of biomass and $50 \% \mathrm{v} / \mathrm{v}$ EtOH as a solvent (Figure 4).

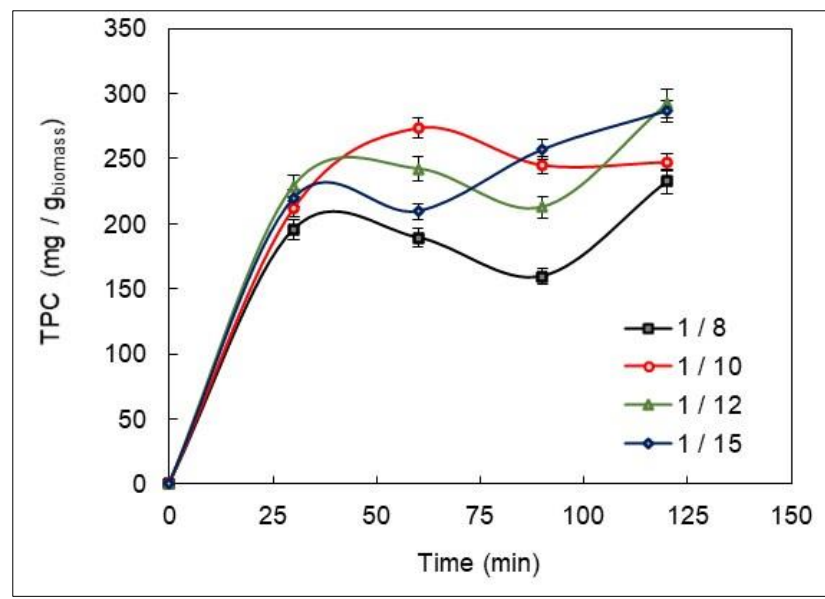

Figure 4. Influence of the extraction time on TPC separated from Rosa canina branches and stems at different solid to liquid ratio

The corresponding kinetic curves (Figure 4) relieved that the TPC extraction takes place in two stages. In the first stage (up to $60 \mathrm{~min}$ ), the rate of extraction related to scrubbing and dissolution supplied by the fresh solvent is significant while the second one is much slower and occurs when the solutes transfer through molecular diffusion from the solid to liquid. After the first $60 \mathrm{~min}$, the diffusion rate decreases with the increase of the extraction time. However, the highest TPC value ( $273.17 \mathrm{mg} / \mathrm{g}$ biomass) was obtained at $60 \mathrm{~min}$, for a solid to liquid ratio of 1:10. For 1:12 and 1:15 solid to liquid ratios, comparative values are obtained $(291.81 \mathrm{mg}$ TPC/g biomass and $286.19 \mathrm{mg}$ $\mathrm{TPC} / \mathrm{g}$ biomass, respectively) at extraction time of $120 \mathrm{~min}$. 


\subsection{Kinetic modelling}

The main goal of this approach is to describe how efficiently were extracted the condensed tannins in HRE extraction. In this regard, two diffusion kinetic models (unsteady diffusion, parabolic diffusion), a second order model as well as some empirical models (Peleg, Page, Weilbull, Elovich) were applied.

The most appropriate kinetic model to elucidate of mechanism of the TPC extraction of Rosa canina branches using HRE method was the second-order rate law. The experimental data were processed using a second-order model by plotting in the specific coordinates, $t / C_{t}$ versus $t$ (Figure 5).

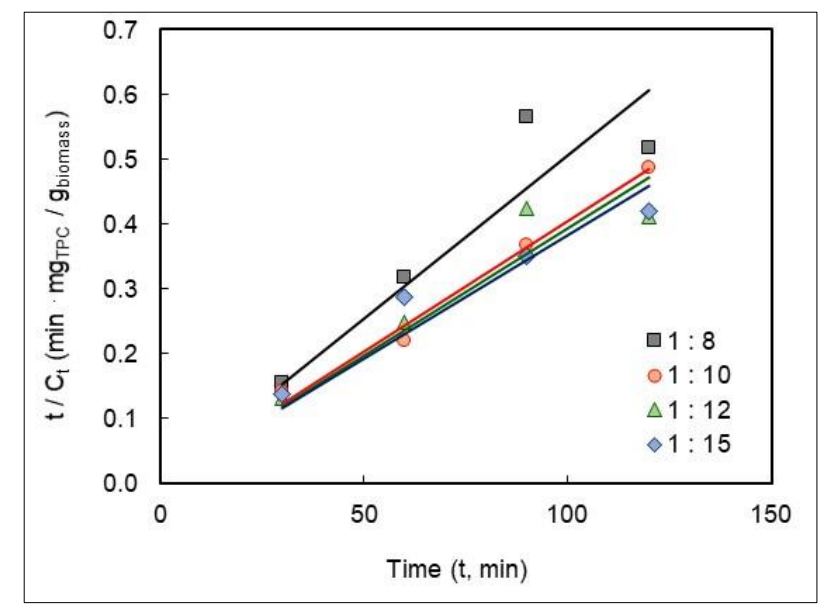

Figure 5. Linearized form of second-order kinetics model of TPC extraction of Rosa canina branches and stems at different solid to liquid ratio

The kinetic parameters, such as concentration at equilibrium $\left(C_{e}\right)$, extraction rate constant $(k)$ and initial extraction rate $(h)$ were calculated based on the linear regression equation for each solid to liquid ratio. A good fit of the second-order kinetic model for all experimental data is confirmed by the value of regression coefficient $\left(\mathrm{R}^{2}>0.910\right)$. The values are reported in Table 1 .

Table 1. Parameters of second-order kinetics of TPC extraction from Rosa canina branches and stems variable solid to liquid ratio

\begin{tabular}{ccccccc}
\hline $\begin{array}{c}\text { Solid to liquid ratio } \\
(\mathrm{g} / \mathrm{mL})\end{array}$ & $\mathrm{A}=1 / \mathrm{h}$ & $\mathrm{B}=1 / \mathrm{C}_{\mathrm{e}}$ & $\begin{array}{c}\mathrm{C}_{\mathrm{e}} \\
\left(\mathrm{mg} / \mathrm{g}^{1}\right)\end{array}$ & $\begin{array}{c}\mathrm{k} \\
(\mathrm{g} / \mathrm{mg} \cdot \mathrm{min})\end{array}$ & $\begin{array}{c}\mathrm{h} \\
(\mathrm{mg} / \mathrm{g} \cdot \mathrm{min})\end{array}$ & $\mathrm{R}^{2}$ \\
\hline $1: 8$ & 0.0215 & 0.0048 & 208.33 & $1.07 \cdot 10^{-3}$ & 46.51 & 0.9146 \\
$1: 10$ & 0.0040 & 0.0035 & 285.71 & $3.06 \cdot 10^{-3}$ & 250.00 & 0.9935 \\
$1: 12$ & 0.0198 & 0.0037 & 270.27 & $0.69 \cdot 10^{-3}$ & 50.51 & 0.9384 \\
$1: 15$ & 0.0282 & 0.0035 & 285.71 & $0.43 \cdot 10^{-3}$ & 35.46 & 0.9648 \\
\hline
\end{tabular}

\subsection{Validity of the developed model}

The total polyphenols (expressed in catechin) concentration obtained using Eq. (4) was compared with the experimental results in the same operating conditions: extraction time $60 \mathrm{~min}$ and variable solid to liquid ratios (Figure 6) and solid to liquid ratio of 1:10 and variable extraction time (Figure 7). 


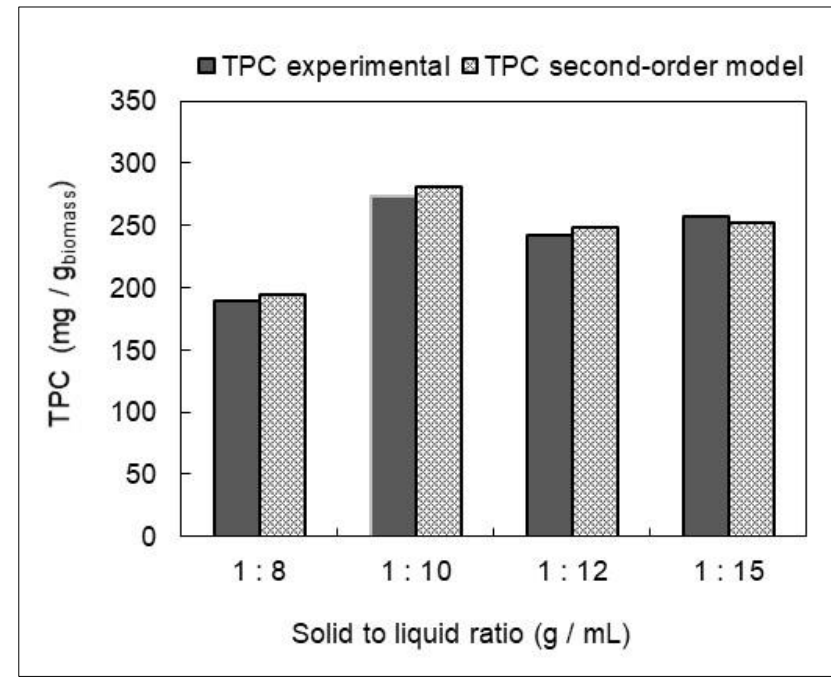

Figure 6. Validation of second-order model for TPC extraction from Rosa canina branches and stems using extraction time of $60 \mathrm{~min}$ at variable solid to liquid ratio

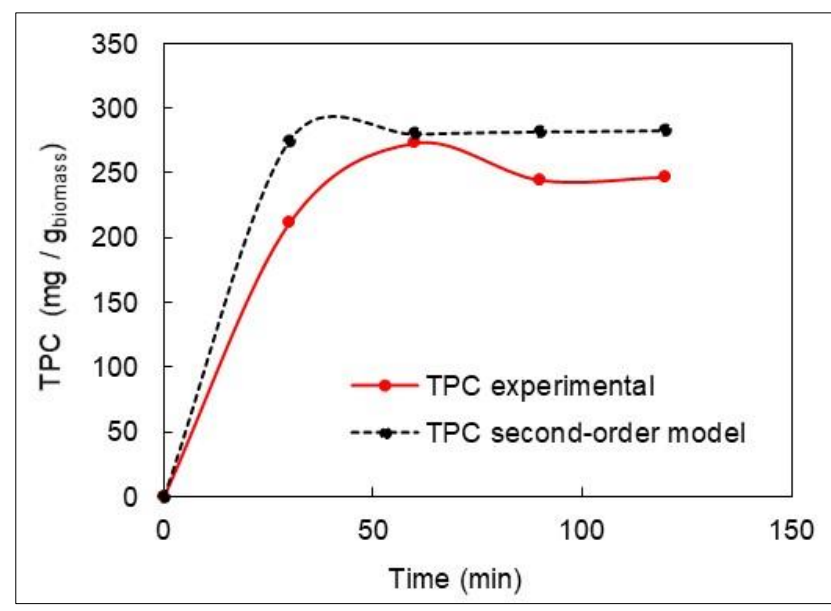

Figure 7. Validation of second-order model of TPC extraction from Rosa canina branches and stems using a 1:10 solid to liquid ratio

The predicted and experimental data were consistent with coefficients of second-order kinetics model. The results proved that the developed second-order model is valid for the HRE extraction of condensed tannins from Rosa canina branches and stems.

\section{Conclusions}

This study point out that the extraction of condensed tannins (expressed as total polyphenols content) from Rosa canina branches and stems is influenced by the extraction method, the solvent concentration, the solid to liquid ratio and by extraction time.

The kinetic of condensed tannins extraction from Rosa canina branches and stems using HRE method was explained using a second-order model, which was further supported by a significant correlation between the experimental results and the calculated ones. The higher polyphenols concentration $(273.17 \mathrm{mg} / \mathrm{g}$ biomass) was obtained in $60 \mathrm{~min}$ and for a solid to liquid ratio of 1:10 using ethanol $50 \% \mathrm{v} / \mathrm{v}$ as solvent. A kinetic study of condensed tannins extracted from Rosa canina branches and stems allow to elucidate the phenomena involved in the process and to a calibration of a 
pilot or scale up process. The second-order model also offers its simplicity for practical application.

\section{References}

1.WINK, M., Modes of action of herbal medicines and plant secondary metabolites, Medicines, 2(3), 2015, 251-286, https://doi: 10.3390/medicines2030251.

2.TONTHUBTHIMTHONG, P., CHUAPRASERT, S., DOUGLAS, P., LUEWISUT THICHAT W. J., Supercritical $\mathrm{CO}_{2}$ Extraction of nimbin from neem seed-an experimental study, J. Food Eng., 47, 2001, 289-293.

3.ARCEUSZ, A., WESOLOWSK, M., KONIECZYNSKP, Y., Methods for extraction and determination of phenolic acids in medicinal plant. A review, Nat. Prod. Commun., 8, 2013, 18211829.

4.PASRIJA, D., ANANDHARAMAKRISHNAN, C., Techniques for extraction of green tea polyphenols: a review, Food Bioprocess Technol., 8(5), 2015, 935-950.

5.VOLF, I., POPA, V. I., Integrated Processing on Biomass Resources for Fine Chemical Obtaining: Polyphenols, in Biomass as renewable raw material to obtain bioproducts of high-tech value, Elsevier, 2018, 113-160, https://doi.org/10.2016/B978-0-444-63774-1.00004-1.

6.SELAHVARZIAN, A., ALIZADEH, A., BAHARVAND, P.A., ELDAHSHAN, O.A., RASOULIAN, B., Medicinal properties of Rosa canina L., Herbal Medicines Journal, 3(1), 2018, 1-8 https://doi.org/10.22087/hmj.v0i0.615.

7.DÍAZ-GÓMEZ, R., LÓPEZ-SOLÍS, R., OBREQUE-SLIER, E., TOLEDO-ARAYA, H., Comparative antibacterial effect of gallic acid and catechin against Helicobacter pylori, LWT - Food Sc. Technol., 54(2), 2013, 331-335.

8.BUJOR, O.C., TALMACIU I.A., VOLF, I., POPA, V.I., Biorefining as a possibility to recovery aromatic compounds with biological properties, TAPPI J., 4, 2015, 187-193.

9.HAINAL, A.R., IGNAT, I., VOLF, I., POPA, V.I., Transformation of polyphenols from biomass by some yeast species, Cell. Chem. Technol., 45(3-4), 2011, 211-219.

10.TANASE C., TALMACIU A., BARA C.I, BOZ I., VOLF I., POPA V.I., New aspects of biomass waste valorisation: Spruce bark crude extracts as plant growth regulators, BioResources, 13(2), 2018, 3994-4007.

11.BILIR, N., Fertility variation in wild Rose (Rosa canina) over habitat classes, Int. J. Agric. Biol., 13(1), 2011, 110-114.

12.WINTHER, K., CAMPBELL-TOFTE, J., HANSEN, A.S., Bioactive ingredients of rose hips (Rosa canina L.) with special reference to antioxidative and anti-inflammatory properties: in vitro studies, Botanics: Targets and Therapy, 5, 2015, 1-13.

13.CIUPERCA, O.T., TEBRENCU, C.E., VOLF, I., Polyphenolic content evaluation in branches of Rosa canina L. and Hippophae rhamnoides L. species, Bulletin of the Polytechnic Institute of Jassy, section Chemistry and Chemical Engineering, 63(67), 2017, 50-58.

14.IGNAT, I., VOLF, I., POPA, V. I., Chap. 67, Analytical Methods of Phenolic Compounds. In: Ramawat, K.G., Merillon, J.M. (Eds.), Hand-book of Natural Products, Springer-Verlag, Berlin Heidelberg, 2013, pp. 2063-2091, https://doi.org/10.1007/978-3-642-221444-6_56.

15.PĂTRĂUŢANU, O.A., LAZĂR, L., POPA, V.I., VOLF, I., Influence of particle size and size distribution on kinetic mechanism of spruce bark polyphenols extraction, Cell. Chem. Technol., 53(12), 2019, 71-78.

16.CIUPERCĂ, O.T., TEBRENCU, C.E., IONESCU, E., IACOB, E., VOLF, I., Studies on polyphenols isolated from branches of Prunus spinosa L. species, Rev. Chim., 70(8), 2019, 2897-2902. 17.LUQUE DE CASTRO, M.D., GARCIA-AYUSO, L.E., Soxhlet extraction of solid materials: An outdated technique with a promising innovative future, Anal. Chim. Acta, 369, 1998, 1-10.

18.AMEER, K., SHAHBAZ, H.M., KWON, J.H., Green extraction methods for polyphenols from plant matrices and their byproducts: a review, Compr. Rev. Food Sci. Food Saf., 16, 2017, 295-315. 
19.TALMACIU, I.A., VOLF, I., POPA, V.I., A comparative analysis of the "Green" techniques applied for polyphenols extraction from bioresources, Chem. Biodivers., 12(11), 2015, 1635-1651.

20.FERREIRA, J.P.A., MIRANDA, I., GOMINHO, J., PEREIRA, H., Selective fractioning of Pseudotsuga menziesii bark and chemical characterization in view of an integrated valorization, Ind. Crops. Prod., 75, 2015, 998-1007.

21.KITANOVIĆ, S., MILENOVIĆ, D., VELJKOVIĆ, V.B., Empirical kinetic models for the resinoid extraction from aerial parts of St. John`s wort (Hypericum perforatum L.), Biochem. Eng. J., 41, 2008, $1-11$.

22.JOKIC, S., VELIĆ, D., BILIĆ, M., BUCIĆ-KOJIĆ, A., PLANINIĆ, M., TOM, S., Modelling of the process of solid-liquid extraction of total polyphenols from soybeans, Czech. J. Food Sci., 28, 2010, 206-212.

23.PASCU (NEAGU), M., PASCU, D.E., TRAISTARU, G.A., BUNACIU, A.A., ORBECI, C., NECHIFOR, A.C., Kinetic studies of some biological active extracts with antioxidant properties, Rev. Chim., 64(8), 2013, 785-790.

24.CHAN, C.H., YUSOFF, R., NGOH, G.C., Modeling and kinetics study of conventional and assisted batch solvent extraction, Chem. Eng. Res. Des., 92, 2014, 169-186.

25.LAZĂR, L., TALMACIU, I.A., VOLF, I., POPA, V.I., Kinetic modeling of the ultrasound-assisted extraction of polyphenols from Picea abies bark, Ultrason. Sonochem., 32, 2016, 191-197.

26.CHEW, K.K, KHOO, M.Z., NG, S.Y., THOO, Y.Y., WAN AIDA, W.M., HO, C.W., Effect of ethanol concentration, extraction time and extraction temperature on the recovery of phenolic compounds and antioxidant capacity of Orthosiphon stamineus extracts, IFRJ, 18(4), 2011, 14271435 .

27.GHIȚESCU, R.E., VOLF, I., CĂRĂUȘU, C., BÜHLMANN, A.M., GÎLCĂ, I.A., POPA, V.I., Optimization of ultrasound-assisted extraction of polyphenols from spruce wood bark, Ultrason. Sonochem., 22, 2015, 535-541.

28.PREDESCU, N.C., PAPUC, C., NICORESCU, V., GAJAILA, I., GORAN, G.V., PETCU, C.D., STEFAN, G., The Influence of solid-to-solvent ratio and extraction method on total phenolic content, flavonoid content and antioxidant properties of some ethanolic plant extracts, Rev. Chim., 67(10), 2016, 1922-1927.

$\overline{\text { Manuscript received: } 16.05 .2020}$ 